\title{
Systemic Arterial-to-Pulmonary Artery Shunt Utilization
}

Awori Mark, Mohamed Ahmed Ali, Mohammed Khan Nabil

School of Medicine, University of Nairobi

Correspondence to: Dr. Mark Awori, P. O Box 14677-00800 Nairobi, Kenya. Email: mnawori@yahoo.com

\begin{abstract}
Background: Congenital heart disease (CHD) is a significant cause of childhood morbidity and mortality worldwide. Treatment often involves systemic arterialto-pulmonary artery shunts (SAPAS); local data is sparse. Methods: A retrospective study was carried out at the Kenyatta National Hospital in Nairobi (Kenya) between January 1st 2006 and December the 31st 2012. All patients who received a SAPAS at the institution during the study period were included. Results: Twenty-four SAPAS were performed on 22 patients. Ten of 24 SAPAS's (41.7\%) were central shunts and 14 of 24 SAPAS's (58.3\%) were modified Blalock-Taussig shunts. The median age and median weight were 20 months (range 3-120) and 11.6 kilograms (range 4.7-23) respectively. The median pre-operative and postoperative arterial oxygen saturations were $68 \%$ (range:
\end{abstract}

29-92) and $89 \%$ (range 52-100) respectively. Postoperative heparin was used in 4 of 23 shunt procedures $(17.4 \%)$. The in-hospital operative mortality was $25 \%$. Median length of post-operative follow-up was 1 year; 95\% were lost to follow-up. Four out of 22 patients $(18.2 \%)$ had a subsequent definitive palliative procedure. Conclusion: The utilization of SAPAS's is not optimal; this may be related to the poor postoperative follow up of our patients. Further study is required to determine the reasons for poor follow-up.

Key words: Blalock Taussig, Shunt

Ann Afr Surg. 2017; 14(2):96-99

DOI:http://dx.doi.org/10.4314/aas.v14i2.9

(C) 2017 Author. This work is licensed under the Creative Commons Attribution 4.0 International License.

\section{Introduction}

Congenital heart disease (CHD) is a significant cause of childhood morbidity and mortality worldwide (1). Treatment is primarily surgical and current practice is to either restore the normal anatomy within the first 6 months of life (2), or to create a definitive palliative alternative anatomical arrangement by 4 years of age (3). In certain circumstances, such as cyanotic neonates with tetralogy of Fallot (4) or cyanotic patients with Tetralogy of Fallot and hypoplastic pulmonary arteries (5), better outcomes are obtained if definitive surgery (total correction or palliation) is preceded by creation of a systemic arterial-to-pulmonary artery shunt (SAPAS). SAPAS may be peripheral or central; there is a dearth of local data on SAPAS use (6). The first report in the literature of the use of a peripheral shunt (PS) to treat a human being was by Blalock in 1945 (7). The right subclavian artery was connected to the right pulmonary artery to increase pulmonary blood flow and alleviate cyanosis. This procedure is known as the classical Blalock-Taussig shunt (CBTS). It has been modified in contemporary practice by using prosthetic material and is now known as the Modified Blalock-Taussig Shunt (MBTS) (8). Davidson reported creating a central shunt (CS) by connecting the ascending aorta directly to the main pulmonary artery (9). This procedure has been modified using prosthetic material and is called the modified Davidson shunt (10). The aim of our study was to determine the indications for and outcomes of SAPAS in our setting.

\section{Methods}

Our study was a retrospective, descriptive study carried out at the Kenyatta National Hospital (KNH) in Nairobi, 
Kenya between January 1st 2006 and December the 31st 2012. The investigators identified relevant patients using the cardiothoracic theatre register. Patient case notes were then retrieved and the relevant data was entered into a data sheet. All patients who underwent a SAPAS procedure at $\mathrm{KNH}$ during the study period were included. Patients who were admitted to KNH but had received a SAPAS at another institution during the study period were excluded. Variables collected included: type of cardiac lesion, type of SAPAS performed, age at surgery, indication for surgery, use of postoperative anticoagulation, length of intensive unit stay and operative mortality. Microsoft Excel (2010) was used for data analysis; there was no missing data. The study was carried out after approval by the Kenyatta National Hospital/University of Nairobi Ethics and Research Committee.

\section{Results}

Over the study period, twenty-four SAPAS were performed on 22 patients. The lesions in the shunted patients are shown in Table 1.

Table 1 Cardiac lesion in SAPAS patients

\begin{tabular}{|l|l|}
\hline Cardiac Lesion & Number (\%) \\
\hline Tetralogy of Fallot (TOF) & $11(45.8)$ \\
\hline Tricuspid atresia (TA) & $7(29.2)$ \\
\hline $\begin{array}{l}\text { Double outlet right } \\
\text { ventricles (DORV) }\end{array}$ & $6(25)$ \\
\hline
\end{tabular}

Ten $(41.7 \%)$ of these were central shunts (CS) and 14 $(58.3 \%)$ were modified Blalock-Taussig Shunts (MBTS). Four of the 14 MBTS (28.6\%) were performed on the right side. The median age and median weight at shunt surgery were 20 months (range 3-120) and 11.6 kilograms (range 4.7-23) respectively. The median pre-operative and post-operative arterial oxygen saturations were $68 \%$ (range: $29-92$ ) and $89 \%$ (range 52-100) respectively.

All shunts were made of expanded polytetrafluoroethylene (ePTFE) and created using continuous prolene. The median shunt diameter was $5 \mathrm{~mm}$ (range 3.5-7). The median duration of surgery was 4 hours (range 3.5-5). Within 12 hours of completion of surgery, intravenous heparin was used in 4 of 23 shunt procedures (17.4\%). Long-term postoperative aspirin was used in 7 of 23 shunt procedures
(30.4\%); the rest of the patients did not receive any anticoagulant. The median length of intensive care stay (LOICUS) and the median length of hospital say (LOHS) were 3 days (range 2-82) and 8.5 days (range 5 - 48) respectively. The in-hospital operative mortality was $25 \%$ (6 deaths). The median length of post-operative follow-up was 1 year (range 1 to 6). Four out of 22 patients (18.2\%) had a subsequent definitive palliative procedure; we could not tell if any patient had a corrective procedure. At the time of data collection, 20 of 22 patients (91\%) had not been seen in the clinic for the last 2 years.

\section{Discussion}

The median age at SAPAS (MBTS or CS) surgery in our patients was 20 months; no SAPAS was performed in neonates. In contemporary best practice, MBTS are primarily performed in neonates (11); the aim is to alleviate cyanosis and to facilitate subsequent definitive surgical procedures. It is not clear why no shunts were performed in neonates, however, a previous study (carried out at the same hospital) on the management pathway of CHD showed that the mean age at which CHD was first confirmed by echocardiography was 18.6 months(6). The authors also noted that the mean age at which CHD was first suspected was 9.5 months. It is likely that CHD is not recognized in the majority of neonates in our setting. This is a concern as the prognosis of cyanotic neonates who do not receive timely intervention is poor. It is not unreasonable to postulate that most neonates requiring SAPAS in our setting die before a diagnosis of CHD is made. Sixteen of 24 shunt procedures $(66.7 \%)$ were on patients with hypoplastic branch pulmonary arteries(BPA's); 8 of 16 patients with hypoplastic BPA's (50\%) received a single PS and the rest received a single CS. Nakata showed that poor surgical outcomes(death) are obtained when total surgical correction is attempted in patients with hypoplastic BPA's(5). SAPAS's are used to 'grow' BPA's to facilitate total correction or optimal definitive palliation. In this regard, CS's have been shown to grow hypoplastic BPA's sufficiently in accordance with Nakata's recommendations (12). There appears to be conflicting evidence as to whether peripheral shunts (CBTS and MBTS) grow BPA's sufficiently $(13,14)$; this may explain why surgical opinion and practice 
differ in regard to the most suitable shunt in a setting of hypoplastic BPA's. Work by Borowski et al provides an explanation for the apparent conflict of evidence (15). Their work shows that BPA growth depends on shunt size and the duration that the shunt has been in place. They noted that to obtain adequate BPA growth, more than one PS is usually required (i.e. a second operation is necessary after some time). In addition, when the duration of time required for adequate BPA growth in their paper is compared to CS outcomes reported in the literature, it is clear that a PS takes a longer time to achieve adequate BPA growth. These two concepts are important to appreciate as they greatly affect surgical decision making. Their implications may be summarized as follows:

1. A single CS will be sufficient to achieve adequate BPA growth but more than one PS will be required to achieve adequate growth.

2. It will take longer to achieve adequate BPA growth using a PS than a CS.

Another concept also affects the choice of shunt used: there is evidence that a CS is a risk factor for operative mortality (16). Considered together, these three concepts provide reasonable arguments for the use of either shunt. The hospital mortality of $25 \%$ is quite high compared to the $10 \%$ reported in the literature $(17,18)$; two factors may have contributed to this. First, our patients are older than the typical patient in contemporary practice. Having lived with the pathology for longer they may represent a sicker cohort of patients. Secondly, only $17.4 \%$ of our patients received heparin post-operatively and only $30.4 \%$ received post-operative acetylsalicylic acid. Although more recent evidence suggests that failure to administer postoperative heparin (19) and aspirin (20) are risk factors for operative mortality, older evidence suggested that post operative intravenous heparin (21) and oral aspirin (22) were unnecessary. This may explain why a large number of patients in our cohort didn't receive them. Over $50 \%$ of SAPAS patients did not present for a single follow-up visit. The remainder only presented for one follow-up visit; $95.5 \%$ were lost to follow-up. Only $18.2 \%$ went on to have definitive palliative surgery (we cannot tell if any had total corrective surgery). This poor progression to the next surgical procedure it probably due to the extremely poor follow-up. The poor quality of follow-up is worrisome as a single SAPAS will not provide longterm palliation (23) nor will a single PS produce adequate growth of BPA's. It is likely that a significant number of these children have died. This is a tragedy in an era when $90 \%$ of children with CHD reach adulthood and experience a good quality of life after having either a total correction or a definitive palliative surgical procedure (24).

\section{Conclusion}

Our findings suggest that the utilization of SAPAS in our setting is not optimal and that this may be related to poor patient follow-up. Future studies should determine the reasons for poor follow-up with a view to providing data that may be used to improve this aspect of care.

\section{References}

1. Liu L, Johnson HL, Cousens S, et al. Global, Regional, and National Causes of Child Mortality: An Updated Systematic Analysis for 2010 with Time Trends Since 2000. The Lancet 2012; 379:2151-61.

2. Karl TR. Tetralogy of Fallot: Current Surgical Perspective. Ann Pediatr Card. 2008; 1: 93-100.

3. Said SM, Burkhart HM, Dearani JA. The Fontan Connections: Past, Present and the Future. World J Pediatr Congenit Heart Surg 2012; 3:171-82.

4. Vohra HA, Adamason L, Haw MP. Is Early Primary Repair for Correction of Tetralogy of Fallot Comparable to Surgery after 6 Months of age? Interact Cardio Vasc Thorac Surg. 2008; 7:698-701.

5. Nakata S, Imai Y, Yakanashi Y et al. A New Method for Quantitative Standardization of Cross Sectional Areas of the Pulmonary Arteries in Congenital Heart Diseases with Decreased Pulmonary Blood Flow. J Thorac Cardiovasc Surg. 1984; 88:610-9.

6. Awori MN, Ogendo SW, Gitome SW, Ong'uti SK, Obonyo NG. Management Pathway for Congenital Heart Disease at Kenyatta National Hospital, Nairobi. East Afr Med J. 2007; 84: 312-7.

7. Blalock A, Taussig HB. The Surgical Treatment of Malformations of the Heart in which there is Pulmonary Stenosis or Pulmonary Atresia. JAMA. 1945; 128:189-92. 
8. De Leval MR, McKay R, Jones M, et al. Modified Blalock-Taussig Shunt. Use of Subclavian Artery Orifice as Flow Regulator in Prosthetic SystemicPulmonary Artery Shunts. J Thorac Cardiovasc Surg. 1981; 81:112-9.

9. Davidson JS. Anastomosis between the Ascending Aorta and the Main Pulmonary Artery in the Tetralogy of Fallot. Thorax 1955; 10:348-50.

10. Barragry TP, Ring WS, Blatchford JW et al., Central Aorta-pulmonary Artery Shunts in Neonates with Complex Cyanotic Congenital heart Disease. J ThoracCardiovascSurg1987; 93:767-74.

11. Pearl JM, Nelson DP, Schwartz SM, et al., Firststage Palliation for Hypoplastic Left Heart Syndrome in the Twenty-first Century. Ann Thorac Surg2002; 73:331-9.

12. Chowdhury UK, Venugopal P, Kothari SS, et al. Criterions for Selection of Patients for, and Results of, a New Technique for Construction of the Modified Blalock Taussig shunt. Cardiol Young. 2006; 16:463-73.

13. Godart F, Qureshi SA, Simha A, et al. Effects of Modified and Classic Blalock-Taussig Shunts on the Pulmonary Arterial Tree. Ann Thorac Surg. 1998; 66:512-7.

14. Gale AW, Arciniegas E, Green EW et al., Growth of the Pulmonary Anulus and Pulmonary Arteries after the Blalock-Taussig Shunt. J ThoracCardiovascSurg1979; 77:459- 65.

15. Borowski A, Reinhardt H, Schickendantz S, et al. Pulmonary Artery Growth after Systemic-topulmonary Shunt in Children with a Univentricular Heart and a Hypoplastic Pulmonary Artery Bed: Implications for Fontan Surgery. Jon Heart J. 1998; 39:671-80.

16. McKenzie ED, Khan MS, Samayoa AX, et al. The Blalock-Taussig Shunt Revisited: a Contemporary Experience. Am Coll Surg. 2013;216:699-704.

17. Gazzaniga AB, Elliott MP, Sperling DR, et al. Microporous Expanded Polytetrafluoroethylene Arterial Prosthesis for Construction of Aortopulmonary Shunts: Experimental and Clinical Results. Ann ThoracSurg1976; 21:322-7.

18. Dirks V, Prêtre R, Knirsch W, et al .Modified Blalock Taussig Shunt: A not-so-simple Palliative
Procedure. Eur J Cardiothorac Surg. 2013; 44:1096-102.

19. Li JS, Yow E, Berezny KY, et al. Clinical Outcomes of Palliative Surgery Including a Systemic-to-Pulmonary Artery Shunt in Infants With Cyanotic Congenital Heart Disease Does Aspirin Make a Difference? Circulation. 2007; 116:293-7.

20. Chittithavorn V, Duangpakdee P, Rergkliang C, et al. Risk factors for in-hospital Shunt Thrombosis and Mortality in Patients Weighing less than $3 \mathrm{~kg}$ with Functionally Univentricular Heart Undergoing a Modified Blalock-Taussig Shunt. Interact Cardiovasc Thorac Surg. 2017; 25:407-13.

21. Mullen JC, Lemermeyer G, Bentley MJ. Modified Blalock-Taussig Shunts: To Heparinize or not to Heparinize? Can J Cardiol. 1996; 12:645-7.

22. Al Jubair KA, Al Fagih MR, Al Jarallah AS, et al. Results of 546 Blalock-Taussig Shunts Performed in 478 Patients. Cardiol Young 1998; 8:486-90.

23. Yoshimura N, Yamaguchi $M$, Ohashi $H$, et al. Growth of the Subclavian Artery and the Anastomosis in Blalock-Taussig Shunt: Absorbable Versus Non-absorbable suture. Ann ThoracSurg1998; 65:1746-50.

24. Warnes C.A, R. Liberthson, G.K. Danielson, et al. Task Force 1: The Changing Profile of Congenital Heart Disease in Adult Life. J Am Coll Cardiol 2001; 37:1170-5. 